\title{
COMPOSIÇÃO DAS EXPORTAÇÕES E CRESCIMENTO ECONÔMICO: UMA
} ANÁLISE ESPACIAL

\author{
Gilberto Libânio ${ }^{1}$ \\ Sueli Moro ${ }^{2}$ \\ Anna Carolina Londe ${ }^{3}$
}

Resumo: Este artigo examina a relação entre composição das exportações e crescimento econômico, para um amplo conjunto de países, entre 2000 e 2010 década marcada por forte elevação dos preços de commodities no mercado internacional. Para tanto, propõe um índice de qualidade de exportações, a partir da classificação em categorias de intensidade tecnológica desenvolvida por Lall (2000). Considerando a presença de dependência espacial nas variáveis, estima-se a relação entre qualidade das exportações e crescimento econômico com a utilização de modelos de painel espacial. Os resultados sugerem que - a despeito da grande expansão da demanda e dos preços de commodities durante a maior parte da década - os países com estruturas exportadoras com maior conteúdo tecnológico apresentaram taxas de crescimento mais elevadas durante o período analisado.

Palavras-chave: Exportações. Tecnologia. Crescimento Econômico. Painel Espacial.

\section{EXPORT COMPOSITION AND ECONOMIC GROWTH: A SPATIAL ANALYSIS}

Abstract: This paper examines the relation between composition of exports and economic growth for a large set of countries, between 2000 and 2010 - a period characterized by a steep rise in commodity prices in international markets. The paper builds an index of exports quality, based on the classification by technological intensity proposed by Lall (2000). Taking into account the existence of spatial correlation among the variables, we estimate the relation between quality of exports and economic growth by using spatial panel data models. The results suggest that despite the boom in commodities demand and prices during most of the decade countries with export structures with higher technological content showed higher growth rates during the period of analysis.

Keywords: Exports. Technology. Economic Growth. Spatial Panel Data.

\section{COMPOSICIÓN DE EXPORTACIONES Y CRECIMIENTO ECONÓMICO: UN ANÁLISIS ESPACIAL}

Resumen: Este artículo examina la relación entre la composición de las exportaciones y el crecimiento económico, para una amplia gama de países, entre 2000 y 2010 - década marcada por un fuerte aumento de los precios de las materias primas en el mercado internacional. Por tanto, propone un índice de calidad de las exportaciones, basado en la clasificación en categorías de intensidad tecnológica desarrollada por Lall (2000). Considerando la presencia de dependencia espacial de las variables, se estima la relación entre la calidad de las exportaciones y el crecimiento económico con el uso de modelos de panel espacial. Los resultados sugieren que, a pesar de la gran expansión de la demanda y los precios de las materias primas durante la mayor parte de la década, los países con estructuras

\footnotetext{
1 Universidade Federal de Minas Gerais, Departamento de Ciências Econômicas, Belo Horizonte, Brasil, gilberto@cedeplar.ufmg.br, https://orcid.org/0000-0002-4583-4346

2 Universidade Federal de Minas Gerais, Departamento de Ciências Econômicas, Belo Horizonte, Brasil, smoro@cedeplar.ufmg.br, https://orcid.org/0000-0002-3034-1813

${ }^{3}$ Economista, Belo Horizonte, Brasil, anna.Ionde@gmail.com, https://orcid.org/0000-0002-2211-4055
} 
exportadoras con mayor contenido tecnológico mostraron mayores tasas de crecimiento durante el período analizado.

Palabras clave: Exportaciones. Tecnología. Crecimiento Económico. Panel Espacial.

\section{INTRODUÇÃo}

A relação entre especialização produtiva, comércio internacional e crescimento econômico é ema de crucial importância para o desenvolvimento, pois as características da estrutura produtiva e exportadora dos diversos países são determinantes para explicar seu desempenho ao longo do tempo.

Kaldor (1957, 1966), por exemplo, enfatizou a importância das exportações e do setor manufatureiro para o crescimento econômico. Por sua vez, Prebisch (1962) e outros autores Cepalinos destacaram como o perfil exportador dos países periféricos (exportadores de produtos primários e importadores de industrializados) representava um obstáculo fundamental ao seu desenvolvimento. Neste sentido, destaca-se a importância da tecnologia e da estrutura tecnológica das exportações, uma vez que produtos de maior intensidade tecnológica e, portanto, maior impacto no valor do total exportado, são comumente produzidos por países de mais elevado grau de desenvolvimento. Na primeira década do século $\mathrm{XXI}$, muito se discutiu sobre as perspectivas de desenvolvimento em um cenário de (re)primarização das exportações dos países emergentes, dada a expressiva elevação da demanda e dos preços de commodities agrícolas e minerais - produtos geralmente caracterizados por um baixo valor agregado, por se localizarem nas etapas iniciais do processo produtivo.

Entender a natureza, determinantes e implicações da estrutura das exportações dos países periféricos é fundamental para compreender suas trajetórias de desenvolvimento atuais e futuras, uma vez que a estrutura tecnológica não pode ser instantaneamente alterada e depende da trajetória anteriormente empreendida.

O objetivo deste trabalho é examinar a relação entre composição das exportações e crescimento econômico, para um amplo conjunto de países, partindo do pressuposto que estrutura tecnológica das exportações tem implicações centrais para o desenvolvimento econômico. Para tanto, propõe um índice de qualidade de exportações, a partir da classificação em categorias de intensidade tecnológica desenvolvida por Lall (2000). Considerando a presença de dependência espacial nas variáveis, estima-se a relação entre qualidade das exportações e crescimento 
econômico com a utilização de modelos de painel espacial, tal como será detalhado adiante, na seção de metodologia.

O período de análise vai de 2000 a 2010, o que permite investigar em que medida a grande expansão da demanda e dos preços de commodities durante a maior parte da década pode ter beneficiado os países menos desenvolvidos, que em geral apresentam pautas de exportações em que tais produtos tem maior relevância.

O presente artigo está organizado em cinco seções, além desta introdução. Na próxima seção, apresenta-se de forma resumida o marco teórico que dá suporte ao trabalho, associado a uma visão Kaldoriana e Schumpeteriana da relação entre exportações, especialização produtiva e crescimento econômico. A seção seguinte descreve brevemente a trajetória do comércio internacional ao longo da última década, com ênfase na classificação das exportações segundo intensidade tecnológica. Em seguida, apresenta-se o índice de qualidade das exportações, bem como a metodologia econométrica e os dados utilizados para estimação. Na quinta seção, analisa-se a relação entre composição das exportações e crescimento econômico no período 2000-2010, com a utilização de modelos de painel espacial, tendo em vista a presença de correlação espacial nos dados. A última seção encerra o artigo com algumas considerações finais.

\section{Tecnologia, Comércio Internacional e Crescimento Econômico}

A importância do desempenho exportador para o crescimento econômico há muito vem sendo ressaltada pela literatura econômica. Mais especificamente, para os propósitos deste artigo, o ponto de partida é a relação entre os padrões de especialização na economia, em particular o papel da estrutura tecnológica das exportações, e o crescimento econômico em longo prazo. Trabalhos de inspiração Schumpeteriana têm abordado essa temática e, portanto, serão tomados aqui como as principais referências.

Neste caso, o foco recai sobre a importância dos mecanismos de geração e difusão da inovação tecnológica para o crescimento e desenvolvimento econômico.

Em geral, considera-se que diferenças internacionais nos níveis de exportações, importações e renda per capita são explicadas por diferenças tecnológicas e de capacidades inovativas entre os países. Ademais, considera-se que tais diferenças não são facilmente superáveis, uma vez que há vários fatores que retardam ou dificultam a difusão da informação entre países, como a existência de patentes, 
informação imperfeita, escassez de infraestrutura cientifica e tecnológica, e a própria dificuldade de adaptação e absorção de novos produtos ou processos por parte das firmas (Dosi, Pavitt and Soete, 1990; Fagerberg, 1994).

Os padrões de alocação de recursos determinados pelo comércio internacional têm implicações dinâmicas que podem ter efeitos de longo prazo tanto benéficos quanto perversos, uma vez que diferentes produtos e setores associam-se a diferentes níveis de oportunidade para inovar e diferentes elasticidades renda da demanda. Sob uma perspectiva Keynesiana/Kaldoriana, as exportações constituem a principal força autônoma de demanda e, portanto, determinam o ritmo de crescimento econômico de um país através de multiplicadores que ajustam a taxa de crescimento do investimento e do consumo. Logo, países que conseguem obter altas elasticidades-renda da demanda internacional por suas exportações tendem a ter também um melhor desempenho econômico.

Por outro lado, sob a perspectiva Schumpeteriana, processos de catch up são parte importante da dinâmica de desenvolvimento dos países, e decorrem de mecanismos de imitação, learning by doing, learning by using, engenharia reversa, incorporação de tecnologias via bens de capital importados, entre outros. Argumenta-se que o processo de imitação de tecnologias já existentes representa uma via alternativa de desenvolvimento para os países tecnologicamente mais atrasados, de modo que esses países não dependam exclusivamente de sua capacidade inovativa - como é o caso dos países líderes - mas também de seu desempenho como imitador. Como o custo relativo da absorção de tecnologias já existentes seria inferior ao da geração de novas tecnologias, os países atrasados tenderiam a apresentar maiores taxas de crescimento da produtividade, o que garantiria a ocorrência de catch up.

Cabe notar que, em tese, o ritmo de avanço tecnológico e de ganhos de produtividade será mais acelerado quanto mais distante um país esteja da fronteira tecnológica. Isto significa que o potencial de crescimento dos países atrasados tende a se reduzir à medida que esses países avançam na incorporação de novas tecnologias, importadas dos países líderes, reduzindo o hiato tecnológico em relação a estes. Entretanto, a eficiência na imitação e absorção de novas tecnologias depende de características estruturais e institucionais dos países, que não são garantidas exclusivamente por seu atraso relativo. Ou seja, a mera ocorrência de atraso tecnológico não garante a incorporação eficiente de tecnologias e, portanto, é necessária a criação de condições adequadas para tanto, associadas principalmente 
à qualificação da mão-de-obra, à existência de instituições de pesquisa e de recursos para seu financiamento. Assim, o resultado esperado do processo de inovação e difusão sobre o crescimento econômico é incerto, e pode dar origem a trajetórias de crescimento em que os países convergem para uma mesma média ou a trajetórias completamente divergentes. (FAGERBERG, 1988)

Segundo a perspectiva Schumpeteriana, portanto, relação entre especialização produtiva e crescimento econômico passa pela capacidade diferenciada de geração e absorção de tecnologias. Assim, diferentes estruturas produtivas trazem consigo diferentes implicações para o crescimento a longo prazo, pois representam diferentes possibilidades de inovação, diferenciação e aprendizado. Estruturas intensivas em tecnologia oferecem melhores perspectivas de crescimento futuro. Tecnologias mais simples, por outro lado, tendem a ter mercados com crescimento mais lento, potencial de aprendizagem mais limitado, menor escopo para avanço tecnológico e menor spillover para outras atividades.

No entanto, estruturas de exportação não são completamente flexíveis e responsivas a mudanças de preços, sendo path-dependent e difíceis de alterar. São o resultado de longos e cumulativos processos de aprendizado, aglomeração, construção institucional e cultura de negócios. Assim, mudanças na estrutura produtiva e exportadora de uma economia, em direção a atividades de maior conteúdo tecnológico, envolvem alto grau de dificuldade e consequentemente requerem um conjunto amplo e integrado de políticas (Lall, 2000). Por isso, é crucial examinar evolução da estrutura tecnológica das exportações de diferentes países e regiões ao longo do tempo, pois a tecnologia é uma das principais variáveis que explica a desigualdade na estrutura do comércio entre os países.

Antes de encerrar a presente seção, cabe fazer breve menção a uma crescente literatura empírica que investiga as relações entre especialização produtiva e crescimento econômico. Não se pretende aqui fazer uma resenha abrangente sobre o tema, mas tão somente reconhecer a existência dessa literatura, a partir da menção a alguns trabalhos selecionados.

Rodrik (2006) elenca uma série de fatos estilizados acerca da relação entre industrialização e crescimento econômico, que confirmam vários argumentos da literatura Kaldoriana e Schumpeteriana, e que podem ser resumidos nas seguintes proposições:

(i) Desenvolvimento econômico requer diversificação, e não especialização; 
(ii) Países com rápido crescimento são aqueles que apresentam grande setor industrial;

(iii) Processos de aceleração do crescimento estão associados a mudanças estruturais em direção ao setor manufatureiro;

(iv) Padrões de especialização não são determinados pela dotação de fatores;

(v) Países que promovem a exportação de produtos mais sofisticados crescem mais rápido;

(vi) Há convergência incondicional ao nível de produtos individuais;

(vii) Alguns padrões de especialização são mais efetivos que outros na promoção do desenvolvimento industrial.

Hausmann, Hwang and Rodrik (2007) argumentam que o mix de produtos que é produzido e exportado por determinado país tem implicações cruciais para seu desenvolvimento. Em particular, sugerem que "countries become what they produce" (Hausmann, Hwang and Rodrik, 2007, p. 2), ou seja, países que se especializam em bens que são tipicamente produzidos por países ricos tendem a crescer mais rápido que aqueles que mantém uma estrutura produtiva centrada em produtos tradicionalmente exportados por países pobres. A partir da construção de um índice de qualidade das exportações, e utilizando dados em cross-section e painel, o trabalho conclui que existe uma relação positiva entre esse índice e o crescimento econômico. ${ }^{4}$

Por fim, cabe mencionar o trabalho de Lederman and Maloney (2009), que investiga a relação entre estrutura produtiva e crescimento, com atenção especial para a chamada "maldição dos recursos naturais". Sua principal conclusão é de que existe uma correlação negativa entre concentração das exportações - medida por um índice de Herfindahl e pela participação de recursos naturais nas exportações e o crescimento econômico. Em particular, conclui-se que:

Arguably, it is concentration per se, and not natural resources in particular, that is negatively correlated with growth. If indeed, there is no "resource curse," but there is a curse of export concentration, the implication is that

\footnotetext{
${ }^{4}$ Embora Hausmann, Hwang and Rodrik (2007) não abordem este ponto, cabe notar que parte expressiva do comércio internacional ocorre por fluxos de bens e serviços intra- e inter-empresas multinacionais que atuam em cadeias globais de valor (CGV). Neste sentido, Costa, Castilho et Anyul (2018) apresentam evidência empírica de que a participação dos países nas CGV depende do grau de complexidade estrutural das diversas economias, o que reforça o argumento de que o melhor desempenho no comércio internacional está associado à produção de bens com maior conteúdo tecnológico.
} 
policy makers should strive to provide a policy framework conducive to product and market diversification ${ }^{5}$ (Lederman and Maloney, 2009, p. 51).

\section{Exportações Segundo Intensidade Tecnológica}

A literatura sobre exportações e desenvolvimento apresenta inúmeras propostas de classificação das exportações segundo os diferentes níveis de intensidade tecnológica. Lall (2000) baseia-se em uma espécie de combinação dos esquemas propostos por OCDE (1994) e Pavitt (1984), de onde segue o esquema que será adotado também neste artigo. Assim, as exportações são classificadas em cinco grandes grupos, a saber:

Produtos primários (PP): apresentam pouco ou nenhum processamento. Exemplos incluem frutas frescas, arroz, cacau, café, soja, madeira, carvão, petróleo bruto, gás.

Manufaturas baseadas em recursos naturais (RB): são em geral produtos simples e trabalho-intensivos, mas há também segmentos que usam tecnologias intensivas em capital, escala, ou técnica, como refino de petróleo ou alimentos processados. Incluem produtos de origem agrícola ou mineral, tais como carnes e frutas processadas, bebidas, produtos de madeira, óleos vegetais, minério de ferro, derivados de petróleo, cimento.

Manufaturados de baixa tecnologia (LT): produtos que utilizam tecnologia estável e bem difundida, geralmente incorporada nos equipamentos de capital. Os mercados para tais produtos tendem a crescer lentamente, e há pouca diferenciação, destacando-se, em muitos casos, a competição via preços. Exemplos incluem vestuário, têxteis, calçados, móveis, brinquedos, artigos de plástico.

Manufaturados de média tecnologia (MT): representa um segmento crucial da atividade industrial nas economias centrais, e compreende a maior parte das tecnologias intensivas em qualificação e escala em bens de capital e intermediários. Tende a apresentar elevadas barreiras à entrada e empregar tecnologias relativamente complexas, com níveis relativamente altos de P\&D, necessidade de qualificação avançada e longos períodos de aprendizagem. Este segmento inclui automóveis e autopeças, fertilizantes, químicos e tintas, siderurgia, motores e máquinas industriais, navios, entre outros.

\footnotetext{
5 "Possivelmente, é a concentração em si, e não os recursos naturais, que é negativamente correlacionada com o crescimento econômico. Se, de fato, não há uma "maldição dos recursos naturais" e sim uma maldição da concentração das exportações, a implicação é que os formuladores de política devem se esforçar em oferecer uma estrutura de políticas propícia a diversificação de produtos e de mercados" (tradução dos autores).
} 
Manufaturados de alta tecnologia $(\mathrm{HT})$ : produtos de tecnologia avançada e em rápida evolução, que se caracterizam por elevados gastos em P\&D e ênfase em design de produto. Neste caso, são incluídos produtos eletrônicos e de telecomunicação, equipamentos de escritório, instrumentos de precisão, indústria farmacêutica e aeroespacial.

Cabe notar que os produtos normalmente definidos como commodities produtos de origem agrícola ou mineral, com baixo valor agregado e baixo grau de processamento industrial, como café, soja, trigo, minério de ferro, cobre, petróleo e gás natural, entre outros - enquadram-se principalmente nos grupos PP e RB. Assim, o boom nos mercados internacionais de commodities observado na primeira década do século XXI, motivado especialmente pela expansão da demanda chinesa, tende a elevar a participação dos grupos PP e RB na pauta de exportação de países produtores de matérias-primas, como de fato ocorreu com o Brasil.

A tabela 1 apresenta as taxas de crescimento e de participação de acordo com as grandes categorias, para o período 2000-2010. No entanto, a análise considera inicialmente uma divisão em cinco subperíodos, de forma a capturar mais adequadamente as distintas dinâmicas pelas quais passou o mercado internacional no período analisado.

No primeiro subperíodo, 2000-2002, as taxas de crescimento foram modestas, provavelmente devido à série de acontecimentos que marcaram o cenário internacional, tais como os atentados terroristas aos EUA em 2001 e a Guerra ao Afeganistão que os sucederam. Especialmente em 2001, as exportações de produtos primários dos países em desenvolvimento tiveram queda acentuada, enquanto os produtos manufaturados mantiveram-se em crescimento.

Os produtos de alta tecnologia também decresceram, puxados pelo crescimento negativo das exportações dos países desenvolvidos (-4,05\%). Para os países em desenvolvimento, houve um pequeno crescimento nessa categoria. Quanto às demais categorias, os países em desenvolvimento obtiveram maiores taxas, destacadamente o grupo de manufaturados de média tecnologia, o que conferiu a este grupo de países o melhor desempenho das exportações de manufaturas.

O subperíodo de 2002 a 2004 é marcado pelo início do boom no mercado de commodities, refletido nas altas de crescimento das exportações, tanto dos países desenvolvidos quanto dos países em desenvolvimento. Como esperado, os produtos primários (PP) e os baseados em recursos naturais (RB) foram os que mais 
cresceram, alcançando taxas superiores a 30\%. Os países em desenvolvimento cresceram cerca de $20 \%$ mais que os países desenvolvidos nas exportações dessas categorias e foram superiores em todas as demais, inclusive na categoria de produtos classificados como alta tecnologia ( $\mathrm{HT}$ ), com um crescimento mais de $30 \%$ acima do crescimento dos países desenvolvidos. Para o mundo e para os dois grupos de países, o ano de 2004 foi o de crescimento mais elevado.

Assim como no subperíodo anterior, 2004-2006 é marcado pelo alto crescimento das exportações mundiais. Os melhores resultados foram alcançados pelos países em desenvolvimento, em todas as categorias de produtos, e com diferenças ainda mais amplas com relação aos países desenvolvidos. Apesar de o maior crescimento dos países em desenvolvimento ter sido alcançado pelos produtos primários, os produtos baseados em recursos naturais tiveram grande elevação em 2004, crescendo a uma taxa superior a 30\%. Para os países desenvolvidos, 2004 também foi o ano de maior expansão do comércio, porém, para eles, o crescimento se deu de forma mais homogênea entre as categorias de produtos.

A partir de 2006, o crescimento das exportações começa a desacelerar, incorrendo em taxas decrescentes ao longo de todo o subperíodo, ao contrário dos anos anteriores, mas não para todas as categorias de produtos. Essa queda deveuse sobretudo à redução das taxas de crescimento das exportações dos países em desenvolvimento, especialmente de produtos primários. Nesse subperíodo, os países desenvolvidos tiveram melhor desempenho.

O subperíodo de 2008 a 2010 é marcado pela grande crise internacional de 2009. É evidente que a crise teve consequências sobre o comércio internacional, que sofreu grande retração. Para os países desenvolvidos, essa retração foi mais acentuada. Mesmo com taxas positivas em 2008 e 2010, 10,62\% e 11,59\%, respectivamente, a queda de mais de $30 \%$ em 2009 foi suficiente para manter a taxa de crescimento total negativa. Para os países em desenvolvimento, esse decréscimo mostrou-se menos acentuado, porém, foi bastante significativo para os produtos primários.

De forma geral, ao longo de todo o período (2000-2010), as exportações mundiais cresceram aceleradamente. Os países em desenvolvimento superaram os países desenvolvidos no crescimento das exportações de manufaturas de baixa, média e alta tecnologia. Mesmo com o período de elevado crescimento do mercado de commodities, as exportações de produtos primários mantiveram-se equilibradas 
entre os dois grupos de países. Entretanto, as exportações de produtos baseados em recursos naturais dos países em desenvolvimento mostraram-se bastante superiores aos países desenvolvidos.

Um dado interessante é que com a crise de 2009, os países desenvolvidos sofreram perdas maiores na quantidade total exportada que os países em desenvolvimento. Somente a exportação de primários sofre perda mais intensa no mundo em desenvolvimento do que no mundo desenvolvido, sendo que, enquanto as exportações de manufaturados do mundo desenvolvido chegaram a decrescer $37 \%$, nos países em desenvolvimento, o decréscimo foi de menos de $20 \%$.

Por outro lado, cabe destacar que, entre 2000 e 2010, o mundo deslocou-se de volta às exportações de produtos primários e menos intensivos em tecnologia, em detrimento dos produtos mais dinâmicos. Entre os países em desenvolvimento, houve um marcado incremento das exportações de PP e RB, com um pequeno incremento da participação de produtos MT na pauta exportadora desses países. Em contrapartida, as pautas tornaram-se menos dinâmicas com a redução da participação de produtos HT e LT.

Tabela 01- Taxas de crescimento e participação das exportações por categoria tecnológica

\begin{tabular}{llllll}
\multicolumn{7}{c}{$(\%)$} & \\
\hline Total & PP & RB & LT & MT & HT
\end{tabular}

Crescimento 2000-2010 (\%)

$\begin{array}{lllllll}\text { Mundo } & 53,54 & 59,56 & 61,50 & 49,26 & 50,46 & 47,61 \\ \text { Desenvolvidos } & 47,44 & 60,44 & 57,00 & 43,69 & 44,96 & 35,03 \\ \text { Em } & 62,94 & 58,60 & 70,43 & 55,77 & 66,51 & 63,66\end{array}$

Participação por categoria no total das exportações mundiais, 2000 e 2010 (\%)

$\begin{array}{lllllll}2000 & 100 & 14,23 & 15,24 & 15,24 & 31,86 & 23,43 \\ 2010 & 100 & 16,45 & 18,51 & 14,05 & 30,08 & 20,91\end{array}$

Participação dos países em desenvolvimento no total das exportações mundiais, 2000 e 2010 (\%)

$\begin{array}{lllllll}2000 & 29,64 & 6,94 & 3,92 & 6,13 & 5,51 & 7,14 \\ 2010 & 37,40 & 7,84 & 6,21 & 6,48 & 7,69 & 9,19\end{array}$

Fonte: Calculado pelos autores a partir dos dados da UN COMTRADE, classificados pelo sistema SITC, três dígitos, revisão 2, e agregados segundo a tipologia proposta por Lall (2000).

Nota: PP, produtos primários; RB, manufaturas baseadas em recursos naturais; LT, manufaturas de baixa tecnologia; MT, manufaturas de média tecnologia; HT, manufaturas de alta tecnologia. 
O Leste Asiático, como esperado, manteve a pauta mais dinâmica entre os países em desenvolvimento e o ganho mais pronunciado de dinamismo, seguindo a tendência iniciada na década de 1990. Apesar de parte da pauta ter se deslocado para os produtos RB, em comparação ao ano 2000, o movimento geral foi de deslocamento dos produtos mais simples para os de maior complexidade.

Outra característica que deve ser mencionada é a consolidação da China como maior exportador entre os países em desenvolvimento. Em 2000, a China liderava apenas as exportações de manufaturas baseadas em recursos naturais e de produtos de baixa tecnologia. Já em 2008, além de ser o país líder mundial no total exportado, os chineses dominaram as exportações de todas as categorias de produtos, exceto de produtos primários - reflexo, entre outros fatores, da ascensão chinesa nas cadeias globais de valor. Isso indica que houve, além de um crescimento substantivo das exportações do país, uma intensa dinamização da pauta exportadora, considerada, aqui, essencial para o crescimento econômico.

Tabela 02- Participação no mercado internacional de acordo com as subcategorias tecnológicas

\begin{tabular}{lcc|cc|cc|cc}
\hline & \multicolumn{3}{c|}{$\begin{array}{c}\text { Participação no mercado } \\
\text { internacional (\%) }\end{array}$} & \multicolumn{3}{c}{ Valor do total de manufaturas } \\
exportadas (US\$ bilhões correntes)
\end{tabular}

Fonte: Calculado pelos autores a partir dos dados da UN COMTRADE, classificados pelo sistema SITC, três dígitos, revisão 2, e agregados segundo a tipologia proposta por Lall (2000).

Dentre os países latino-americanos, o melhor colocado no total exportado é o México, que aparece como quarto maior exportador, no ano 2000, perdendo duas posições em 2008. O desempenho mexicano deve-se, sobretudo, à exportação de produtos de média tecnologia. No início do período, o país era o líder em exportações de MT entre os países em desenvolvimento. Em 2008, porém, perdeu duas posições (para China e Coréia do Sul), tornando-se o sexto colocado. O Brasil, 
segundo maior exportador latino-americano, ganhou posições no período. No ano 2000, o país ocupava a décima posição, no total exportado, passando para a sétima colocação em 2008. A melhoria do desempenho brasileiro está ligada ao aumento das exportações de produtos primários, categoria na qual ganhou seis posições. Destaca-se também a posição brasileira entre os maiores exportadores de alta tecnologia, devido às exportações de aeronaves (décimo maior exportador em 2000 e nono colocado em 2008).

Apesar das posições entre os países que mais exportaram terem se alterado em algumas categorias, o grupo de países que domina as exportações do mundo em desenvolvimento pouco se alterou, principalmente se considerarmos as categorias de maior intensidade tecnológica. Assim, pode ser dito que mesmo com o elevado crescimento do total exportado, tanto mundialmente quanto entre os países em desenvolvimento, as capacidades de desenvolver e aprimorar o desempenho exportador ficaram restritas a um pequeno grupo de países.

\section{Base de Dados e Metodologia}

A primeira etapa do artigo foi proceder a uma revisão da literatura teórica sobre a relação entre estrutura produtiva e crescimento econômico, por meio de pesquisa bibliográfica, de modo a delimitar o marco teórico que orienta a análise desenvolvida a seguir. Foi também apresentada uma breve menção à literatura empírica sobre o tema, que auxilia a guiar a construção das hipóteses centrais deste trabalho.

Para entender como a qualidade das exportações impacta sobre as taxas de crescimento econômico, muitos estudos empíricos procuraram construir índices de qualidade das exportações de diferentes formas (ver HAUSMANN, HWANG, RODRIK, 2007, por exemplo).

O objetivo deste artigo é investigar se a qualidade da estrutura tecnológica das exportações é importante para o crescimento econômico, examinando a hipótese de que uma pauta exportadora tecnologicamente mais avançada está associada a um melhor desempenho econômico. Para tanto, construímos um índice de qualidade (ou sofisticação) das exportações, conforme especificado abaixo.

De acordo com a classificação adotada, as exportações foram divididas em dois grandes grupos, X1 e X2. O primeiro compreende os produtos classificados como primários, manufaturas baseadas em recursos naturais e produtos de baixa tecnologia (PP, RB e LT, respectivamente), ou seja, $\mathrm{X} 1$ representa uma pauta 
exportadora de menor densidade tecnológica. X2, por sua vez, agrupa os produtos de média e alta tecnologia (MT e HT), que compõem pautas mais dinâmicas. Feita essa divisão, foi definido o índice de qualidade das exportações $q_{i t}$, como:

$$
q_{i t}=\frac{X 2-X 1}{\text { Total } \exp \text { ortado }}
$$

Tal índice varia entre -1 e 1. Dessa forma, quanto mais próximo de 1 , maior a qualidade das exportações do país $i$ em $t$. Por conseguinte, quanto mais próximo de -1 , menos sofisticada é a pauta.

O trabalho baseia-se nos dados de valor das exportações, medido em dólares americanos, disponíveis na base de estatísticas de comércio de produtos das Nações Unidas, COMTRADE (acessível pelo portal http://comtrade.un.org/db). Para lidar com a variação da disponibilidade de dados de alguns países ao longo do período, o modelo construído e as análises propostas consideram uma amostra de 167 países que reportaram suas informações consistentemente de 2000 a 2010.

A classificação adotada para as exportações foi a SITC, três dígitos, revisão dois ${ }^{6}$. De acordo com Lall (2000), nessa forma, os dados não permitem captar todos os aspectos da modernização tecnológica, pois idealmente deveriam distinguir entre os diferentes níveis de tecnologias usadas nas atividades exportadoras e sua modernização ao longo do tempo. Apesar disso, a SITC no nível de três dígitos permite uma desagregação considerável, mesmo colocando juntos produtos de distintas intensidades tecnológicas. A classificação também não considera o processo envolvido na montagem de produtos em diferentes localidades, fazendo com que tanto complexos desenvolvimentos como simples montagens possam aparecer na mesma categoria, além de desconsiderar a modernização ocorrida no interior de cada categoria. Dadas essas limitações, os resultados aqui reportados devem ser tomados com cautela. Contudo, as formas de lidar com tais problemas, inerentes aos dados, acarretariam grande perda de informação ou demasiada desagregação, de forma que os custos ultrapassariam os benefícios.

\footnotetext{
${ }^{6}$ SITC (Standard International Trade Classification) é uma das principais classificações utilizadas para a organização de estatísticas de comércio internacional. É publicada pela ONU e permite diferentes níveis de desagregação, com códigos de até cinco dígitos. Esta classificação foi adotada neste trabalho, de modo a permitir a comparabilidade com a metodologia e com a análise desenvolvida por Lall (2000). Outro sistema amplamente empregado para a geração de estatísticas de comércio internacional é o Sistema Harmonizado (SH), que permite a classificação dos produtos em um sistema de até seis dígitos. É possível a conversão de informações entre as classificações SITC e SH, por meio de tabelas de equivalência entre os códigos de produtos.
} 
O modelo a ser estimado é um painel dinâmico da forma:

$$
\begin{aligned}
& y_{i t}=\rho y_{i t-1}+q_{i t} \beta_{1}+t_{d i t} \beta_{2}+u_{i}+\varepsilon i t \\
& \qquad i=\{1, \ldots, 167\} \text { and } t=\{1, \ldots, 11\}
\end{aligned}
$$

Onde yit é a taxa de crescimento do produto, yit-1 é a taxa de crescimento defasada, que captura aos efeitos de possíveis variáveis omitidas, qit é o índice de qualidade das exportações e tdit é um índice de variação dos termos de troca ao longo do período?.

O termo ui é uma variável aleatória não observável, chamada também de variável latente, efeito individual ou heterogeneidade individual dos países. Esse efeito-país pode incluir características geográficas dos países como a localização geográfica além de fatores demográficos, sócio-econômicos, ambientais e culturais que podem ser correlacionados com as variáveis explicativas do modelo ( $q_{i t}$ e td $\left.d_{i t}\right)$ e o termo $\varepsilon$ it representa o vetor de erros i.i.d.

Sabe-se que os métodos usuais de estimação de modelos com dados em painel como efeitos aleatórios, efeitos fixos (transformação interna) e primeirasdiferenças são inadequados para painéis dinâmicos, produzindo estimadores inconsistentes para os parâmetros (Greene, 2007). A extensa literatura teórica e empírica sugere métodos de estimação baseados em variáveis instrumentais com especial ênfase no GMM (Método dos Momentos Generalizado). Desde a introdução do GMM na análise de painéis dinâmicos por Holtz-Eakin, Newey e Rosen (1988), vários refinamentos metodológicos foram introduzidos, a maioria deles baseados em sugestões de instrumentos adequados para maior eficiência da estimação GMM (Arellano et Bond, 1991, Arellano et Bover, 1995, Blundel \& Bond, 1998). Arellano et Bond (1991), sugeriram uma diferenciação das variáveis e posterior estimação por GMM com condições de momentos que usam defasagens da variável dependente em nível e primeiras diferenças das variáveis explicativas estritamente exógenas. Posteriormente, Arellano-Bover (1998) e Blundell-Bond (1998) propuseram o uso de condições de momento adicionais em uma estimação baseada num sistema de duas equações em que a primeira é a equação original em nível e a segunda é uma equação em primeiras diferenças. A equação em nível utiliza os instrumentos em diferenças e a equação em diferenças os instrumentos em nível. Essa metodologia é

\footnotetext{
7 Série calculada como a relação entre o valor unitário das exportações e o valor unitário das importações, medido em relação ao ano base 2000. Fonte: WDI
} 
conhecida como GMM-sistema e melhora substancialmente a eficiência da estimação GMM. Essa foi a metodologia de estimação utilizada neste trabalho.

Entretanto, devido a natureza espacial dos dados utilizados nesse estudo, a autocorrelação espacial dos valores das variáveis entre países na mesma vizinhança geográfica deve ser testada e levada em conta nas estimações, uma vez que com dados espacialmente agregados, os métodos de estimação baseados em variáveis instrumentais podem levar a estimadores inconsistentes dos parâmetros ${ }^{8}$. Assim, foi calculada a estatística I de Moran - medida global de autocorrelação espacial - para as variáveis do painel. A tabela 3 apresenta os resultados.

Observa-se que todas as variáveis mostram um valor significativo do I de Moran e que o índice de qualidade das exportações é a variável que apresenta o maior nível dessa estatística. Mais especificamente, verifica-se que a taxa de crescimento do PIB apresenta alta correlação espacial particularmente em 2009, o que pode ser justificado pelo espraiamento da crise econômica internacional iniciada no ano anterior. Ademais, cabe notar que o índice de qualidade das exportações apresenta significativa autocorrelação espacial consistentemente ao longo de todo o período, o que justifica a necessidade de filtrar a correlação espacial nos dados para estimação. Por fim, observa-se que a variável termos de troca apresentou níveis mais elevados de correlação espacial a partir de 2005, o que provavelmente se relaciona ao movimento consistente de elevação dos preços de commodities agrícolas e minerais no período. 
Tabela 03- Estatística I de Moran

\begin{tabular}{|c|c|c|c|c|c|c|}
\hline \multirow[b]{2}{*}{ Ano } & \multicolumn{2}{|c|}{ Tx_PIB } & \multicolumn{2}{|c|}{ Indice_Qualidade } & \multicolumn{2}{|c|}{ Termos_troca } \\
\hline & I de Moran & $\mathbf{t}$ & I de Moran & $\bar{t}$ & I de Moran & $\mathbf{t}$ \\
\hline 2000 & 0.06 & 1.98 & 0.24 & 6.71 & 0.10 & 5.02 \\
\hline 2001 & 0.02 & 0.84 & 0.25 & 7.24 & 0.09 & 4.52 \\
\hline 2002 & 0.21 & 7.04 & 0.23 & 6.59 & 0.09 & 4.44 \\
\hline 2003 & 0.07 & 1.90 & 0.22 & 6.52 & 0.11 & 5.34 \\
\hline 2004 & 0.12 & 3.63 & 0.24 & 6.98 & 0.13 & 6.36 \\
\hline 2005 & 0.17 & 5.60 & 0.24 & 6.89 & 0.20 & 8.18 \\
\hline 2006 & 0.12 & 4.32 & 0.23 & 6.72 & 0.22 & 8.82 \\
\hline 2007 & 0.15 & 5.14 & 0.27 & 7.81 & 0.23 & 9.24 \\
\hline 2008 & 0.14 & 4.86 & 0.24 & 6.97 & 0.28 & 10.20 \\
\hline 2009 & 0.42 & 11.30 & 0.25 & 7.25 & 0.18 & 7.90 \\
\hline 2010 & 0.17 & 5.16 & 0.25 & 7.14 & 0.23 & 9.30 \\
\hline
\end{tabular}

Fonte: Elaboração própria

O I de Moran, sendo uma estatística global, não ilustra a estrutura de autocorrelação espacial em nível local entre os países; para isto existem as estatísticas locais de autocorrelação espacial, as LISA (local indicator of spatial association). Para ilustrar a presença de autocorrelação espacial no índice de qualidade das exportações dos países, a Figura 1 mostra um mapa com os resultados de uma estatística local desenvolvida por Anselin (1995) e construída a partir da decomposição do I de Moran global para cada país para o ano de 2010. A estatística LISA é definida para cada observação em função da média dos vizinhos. Autocorrelação espacial positiva significa valores similares (altos ou baixos) aos vizinhos indicando a presença de clusters espaciais de altos (high-high) ou baixos valores (low-low). Por outro lado, autocorrelação espacial negativa mostra valores significativamente maiores (ou menores) quando comparado aos vizinhos (high-low e low-high), evidenciando observações atípicas ou outliers espaciais. Neste caso, chama a atenção a presença de clusters espaciais bem definidos na America do Sul e na África, ambos caracterizados por baixa qualidade das exportações. A Europa, por outro lado, apresenta o mais relevante conjunto de países cuja autocorrelação espacial positiva está associada a exportações de maior conteúdo tecnológico.

Figura 01 - Estatística I de Moran local para a qualidade das exportações - 2010 


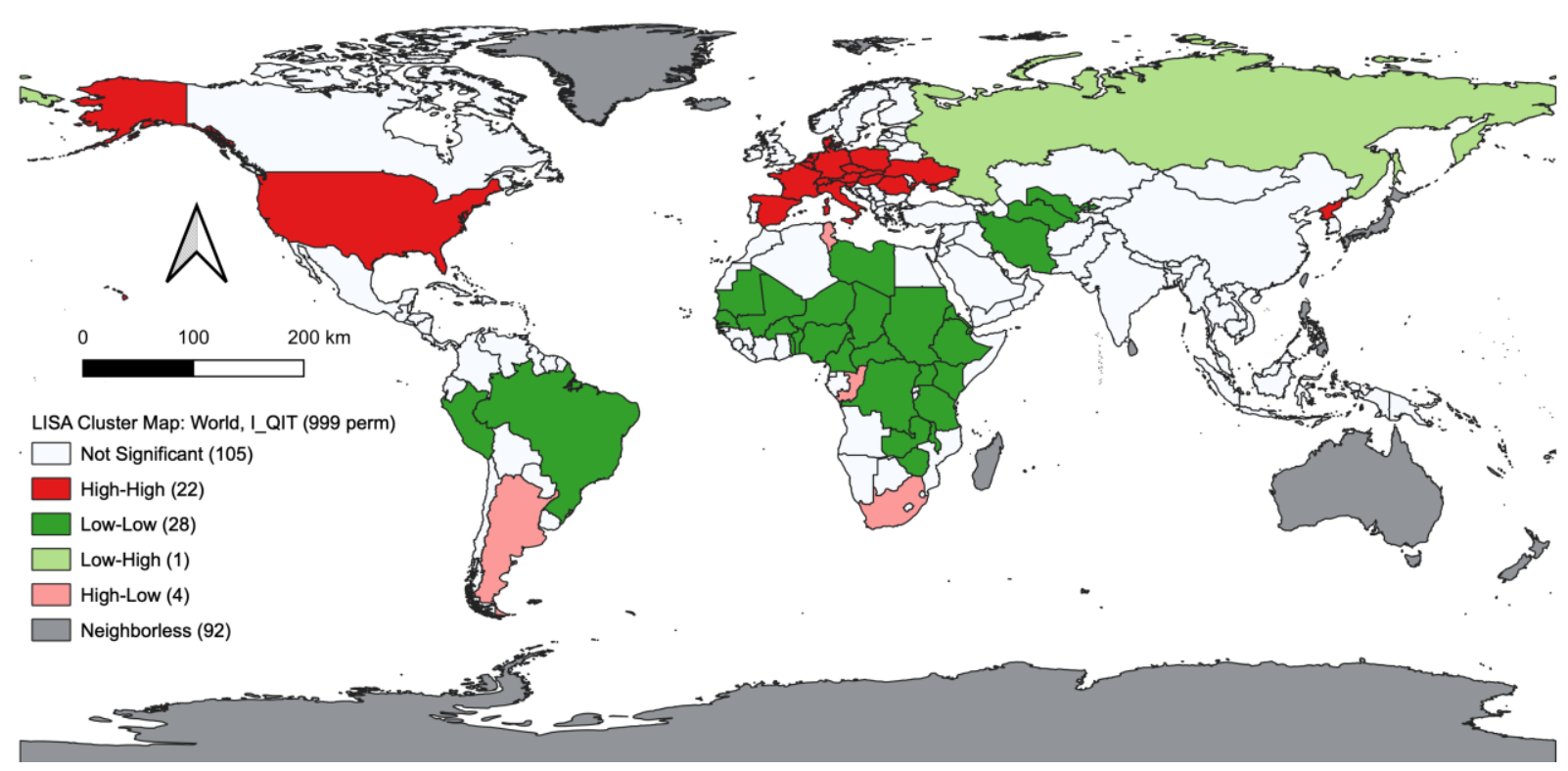

Fonte: elaboração própria

Existem procedimentos bem definidos (Anselin et al, 2004) para estimação de modelos com dados que exibem autocorrelação espacial, como por exemplo os modelos de defasagem espacial, modelos de erro espacial, etc. Entretanto, como neste trabalho o interesse não é uma especificação espacial do modelo dinâmico, a autocorrelação espacial nos dados foi levada em conta através da aplicação de um filtro espacial aos dados antes da estimação do painel pelo GMM-sistema. O filtro, proposto por Anselin (2002) e Anselin, Le Gallo\&Jayet (2008) é do tipo:

$$
\left[I_{T} \otimes\left(I N-\rho W_{N}\right)\right] Y=X \beta+\varepsilon
$$

Onde $Y$ é a taxa de crescimento do PIB e X são as variáveis independentes do modelo ( $q_{i t}$ etdit).

O valor de $\rho$ na equação acima foi obtido pela estimação de um modelo de defasagem espacial do painel.

\section{Qualidade das Exportações e Crescimento Econômico: Uma Estimação}

A partir dos procedimentos descritos acima, foram feitas duas estimações alternativas, a segunda delas incluindo dummies para os anos de análise. Os resultados das estimações podem ser vistos na tabela 4.

Em todas as especificações do modelo (com ou sem as dummies de tempo), o índice de qualidade das exportações aparece com um coeficiente positivo e estatisticamente significativo. Tal resultado confirma a previsão da teoria e sugere que as estruturas exportadoras de melhor qualidade, associadas a um índice positivo, tiveram impacto positivo sobre o crescimento econômico dos países 
considerados, enquanto as pautas de pior qualidade tiveram impacto negativo. A magnitude do impacto é também dada pela qualidade da pauta, uma vez que o efeito restritivo sobre o crescimento é tanto maior quanto menor o valor de $q_{i t}$, o que também seria o esperado, de acordo com a teoria discutida anteriormente. É interessante notar que este resultado é verificado a despeito de se tratar de um período em que, como descrito anteriormente, as categorias de exportações que mais cresceram foram PP e RB. Assim, os resultados das estimações sugerem que o boom no mercado internacional de commodities não levou necessariamente a uma melhor performance econômica dos países com pautas de exportação mais primarizadas.

Tabela 04 - Relação entre a taxa de crescimento do PIB e o índice de qualidade das exportações

Variável dependente: Taxa de crescimento do PIB

$\mathrm{N}=1504 ; \mathrm{T}=167$

Variáveisindependentes

Taxa de cresc do PIB defasada

Indice de qualidade das exportações

Termos de troca

Dummies de ano

2003

2004

2005

2006

2007

2008

2009

2010

Constante

Teste de Wald (3) e (11)

Instrumentos

Teste de Sargan_Hansen

\begin{tabular}{rcrc}
\multicolumn{5}{c}{ GMM - Sistema } \\
\hline Coef & Prob $>\mathbf{z}$ & Coef & Prob $>\mathbf{z}$ \\
0.022 & 0.000 & -0.167 & 0.000 \\
2.890 & 0.000 & 3.135 & 0.000 \\
0.005 & 0.065 & 0.025 & 0.065
\end{tabular}

\section{.}

$\begin{array}{rrrr} & & -0.222 & 0.007 \\ & & 0.948 & 0.000 \\ & & 2.233 & 0.000 \\ & & 1.959 & 0.000 \\ & & 2.723 & 0.000 \\ & & 2.752 & 0.000 \\ & & 1.050 & 0.000 \\ 4.916 & 0.000 & -3.629 & 0.000 \\ & 37.31 & 3.046 & 0.000 \\ 127 & & 4329.280 & 0.000 \\ 157.150 & 0.328 & 127 & \\ & & 103.38 & 0.111\end{array}$

Fonte: Elaboração própria, a partir dos dados da ONU COMTRADE, classificados pelo sistema SITC, três dígitos, revisão 2, conforme metodologia especificada acima. Nota: As dummies de ano não foram significativas para os anos de 2001 e 2002.

\section{Considerações Finais}

Este trabalho procurou examinar a evolução das exportações nos anos 2000, segundo categorias por intensidade tecnológica, baseado na premissa de que 
diferentes estruturas tecnológicas das exportações têm diferentes impactos sobre o crescimento econômico. Como esperado, pautas exportadoras mais dinâmicas mostraram-se relacionadas a um efeito positivo sobre o crescimento econômico.

O chamado boom das commodities teve impacto visível sobre a estrutura das exportações, especialmente dos países em desenvolvimento - como África do Sul, Brasil, Chile, Rússia, entre outros - pois houve um marcante deslocamento do esforço exportador em direção a produtos primários e baseados em recursos naturais.

Contudo, observa-se que os países que se destacaram como grandes exportadores no período 2000-2010 foram aqueles que mantiveram a tendência de dinamização de suas exportações, iniciada na década anterior. No caso do mundo em desenvolvimento, essa tendência está presente apenas nos países do Leste Asiático, com todos os demais grupos perdendo capacidade de competir internacionalmente em categorias de mais elevada intensidade tecnológica e concentrando suas exportações em produtos mais simples.

Por outro lado, a partir da existência de autocorrelação espacial no perfil exportador dos países, procedeu-se a uma estimação usando painel espacial para um conjunto de 167 países entre 2000 e 2010. Os resultados encontrados sugerem que pautas de exportação com maior conteúdo tecnológico foram mais favoráveis para o crescimento econômico dos países, a despeito do boom do mercado internacional de commodities que caracterizou a década dos 2000.

Como destacado anteriormente, a estrutura tecnológica dos produtos exportados não é passível de modificações imediatas, sendo path-dependent e demandante de grande esforço em prol de uma modificação substantiva. Assim, o esperado é que os países em desenvolvimento que têm se esforçado em busca de uma pauta exportadora mais dinâmica sejam aqueles futuramente capazes de obter os melhores resultados em termos de desenvolvimento econômico a longo prazo.

\section{REFERÊNCIAS}

Anselin, L.; Le Gallo, J.; Jayet, H. Spatial Panel Econometrics. In: Matyas, L.; Sevestre, P. (Eds.). The Econometrics of Panel Data: Fundamentals and Recent Developments in Theory and Practice. 3.ed. Dordrecht: Kluwer, 2008.

Anselin, L.; Florax, R.; Rey, S. (Eds.).Advances in Spatial Econometrics. Methodology, Tools and Applications. Berlin: Springer-Verlag, 2004. 
Arellano, M.; Bover, O. Another look at the instrumental variable estimation of errorcomponents models. Journal of Econometrics,v.68,n.1, p. 29-51, July1995.

Arellano, M.;Bond, S.Some tests of specification for panel data: Monte Carlo evidence and an application to employment equations. Review of Economic Studies, v.58, n.2, p 277297, 1991.

Blundell, R.; Bond, S. Initial conditions and moment restrictions in dynamic panel data models. Journal of Econometrics, v. 87, n.1, p.115-143, Nov. 1998.

Costa, K.; Castilho, M.; Anyul, M. Structure productive et effet d'entraînements productifs à l'ère des chaînes globales de valeur : une analyse input-output. Revue d'économie industrielle, n. 163, p. 147-186.

Dosi, G.; Freeman, C.; Fabiani, S. The process of economic development: introducing some stylized facts and theories on technologies, firms and institutions.Industrial and Corporate Change,v. 3, n. 1, 1994.

Dosi, G.; Pavitt, K.; Soete, L. The economics of technical change and international trade. London: Harvester Wheatsheaf, 1990.

Fagerberg, J. Technology and international differences in growth rates. Journal of Economic Literature, v. 32, n.3, p. 1147-1175, 1994.

Fagerberg, J. Why growth rates differ. In: Dosi, G. et al (Org.). Technical change and economic theory. London: Pinter Publishers, 1988.

Greene, W, H.Econometric Analysis. 7.ed. New York: Prentice Hal, 2012.

Grossman, G. M.; Helpman, E. Innovation and growth in the global economy. Cambridge, MA: The MIT Press, 1991.

Haussmann, R.; Hwang, J.; Rodrik, D. What you export matters. Journal of Economic Growth, Springer, v. 12, n.1, p. 1-25, March 2007.

Holtz-Eakin, D.; Newey, W.; Rosen, H. Estimating Vector Autoregressions With Panel Data. Econometrica, v. 56, n. 6, p. 1371-1395, 1988.

Kaldor, N. Causes of the Slow Rate of Economic Growth of the United Kingdom: an Inaugural Lecture. Cambridge: Cambridge University Press, 1966.

Kaldor, N. A model of economic growth. The Economic Journal, v.67, p. 591-624, 1957.

Lall, S. The technological structure and performance of developing country manufactured exports, 1985-98. Oxford Development Studies, v. 28, n. 3, p. 337-369, 2000.

Lederman, D.; Maloney, W. Trade structure and growth. In: Natural resources, neither curse nor destiny. Washington: The World Bank, 2007.

Londe, A.; Libanio, G. A estrutura tecnológica das exportações dos países em desenvolvimento nos anos 2000: análise e implicações para o crescimento. In: ENCONTRO NACIONAL DE ECONOMIA - ANPEC, 41, 2013, Foz do Iguaçu.

ORGANISATION FOR ECONOMIC COOPERATION AND DEVELOPMENT OECD. Globalisation and Competitiveness: Relevant Indicators, Paris, OECD Directorate for Science, Technology and Industry, DSTI/EAS/IND/WP 9(94)19. 
Pavitt, K. Sectoral patterns of technical change: towards a taxonomy and a theory. Research Policy, v. 13, p. 343-373, 1984.

Prebisch, R. O desenvolvimento econômico da América Latina e alguns de seus problemas principais. In: Bielschowsky, R. (Org.). Cinquenta anos de pensamento na CEPAL. v.1. Rio de Janeiro: Record, 2000.

Rodrik, D. What's so special about China's exports? NBER Working Paper, n. 11947, 2006.

Ros, J. Trade specialization and economic growth. In: Fanelli, J., Medhora R. (eds). Finance and Competitiveness in Developing Countries. New York: Routledge, 2002.

UNCTAD. Trade and Development Report 2009. New York and Geneva: United Nations, 2009.

Wooldridge, J. Econometric Analysis of Cross Section and Panel Data. Cambridge, MA: MIT Press, 2001.

Young, A. Increasing returns and economic progress. Economic Journal, v. 38, p. 527-542, 1928.

\section{NOTAS DE AUTOR}

\section{CONTRIBUIÇÃO DE AUTORIA}

Gilberto Libânio - Concepção. Análise de dados, Elaboração do manuscrito, revisão e aprovação da versão final do trabalho

Sueli Moro - Definição da metodologia; estimação econométrica e elaboração do manuscrito. Participação ativa da discussão dos resultados; Revisão e aprovação da versão final do trabalho.

Anna Carolina Londe - Coleta e organização da base de dados; cálculo dos indicadores. Elaboração do Manuscrito. Revisão e aprovação da versão final do trabalho.

\section{FINANCIAMENTO}

Não se aplica.

\section{CONSENTIMENTO DE USO DE IMAGEM}

Não se aplica.

\section{APROVAÇÃO DE COMITÊ DE ÉTICA EM PESQUISA}

Não se aplica.

\section{CONFLITO DE INTERESSES}

Não se aplica.

\section{LICENÇA DE USO}

Este artigo está licenciado sob a Licença Creative Commons CC-BY-NC. Com essa licença você pode compartilhar, adaptar, criar para qualquer fim, sem uso comercial e desde que atribua a autoria da obra.

\section{HISTÓRICO}

Recebido em: 12-09-2019

Aprovado em: 28-05--2020 